\title{
Kinematic differences between professionals and young players in the tennis serve
}

\author{
Christos Mourtzios ${ }^{\mathrm{a}}$, Ioannis Athanailidis ${ }^{\mathrm{a}}$, Eleftherios Kellis ${ }^{\mathrm{b}}$ \& Vasileia \\ Arvanitidoua.
}

${ }^{a}$ Democritus University of Thrace - Department of Physical Education and Sports, Komotini, Greece.

${ }^{b}$ Aristotle University of Thessaloniki - Laboratory of Neuromechanics, Department of Physical Education and Sports, Serres, Greece.

\begin{abstract}
The aim of the present study was to measure and examine the differences in lower limb kinematics between the flat, slice and topspin serves, in the kinematic features of the lower limbs, at two different times of the service movement, maximum knee bending and point of contact of the racket with the ball, in 12 young tennis athletes, aged 12-16 years and in 12 professional players that they were playing on the main draw of Roland Garros. The results showed no significant differences in time between the three types of service in young athletes. Comparing the time of young athletes $34.56 \mathrm{~ms}$ with the time of high level athletes with $30.67 \mathrm{~ms}$, the results showed that the professionals performed the service faster than the young athletes having a significant difference.
\end{abstract}

Key words: flat, slice, topspin, tennis serve, biomechanics, young tennis athletes, professional tennis players

Received: 20 January 2021

Acepted: 15 March 2021

Corresponding author: Christos Mourtzios. Democritus University of Thrace - Department of Physical Education and Sports, University Campus, 12 Vas. Sofias St., 67132 Komotini, Greece. Email: christosmourtzios@hotmail.gr

\section{INTRODUCTION}

Tennis serve has attracted the attention of research because it is the most important stroke that starts the game (Cross \& Lindsey, 2005). Although it has been well documented that service performance is related to upper extremity movement, very little is known about the impact of lower limps. There are very few research studies that have explored the kinematic characteristics of serve movement in young tennis athletes and much less studies compared the three basic serve types, namely the flat, slice and topspin (Abrams et al., 2011; Elliott, et al., 2009; Reid, Elliott, \& Alderson, 2008; Elliott \& Wood, 1983; Elliott, Fleisig, Nicholls \& Escamilla, 2003). The purpose of this study was to measure and examine the differences that may exist between the three different types of service, flat, slice and topspin, in the kinematic characteristics of the lower limps and in particular the beginning of the take-off which coincides with the time point of contact of the racket with the ball.

As the mechanism of "leg drive» is an important factor for the efficiency and speed of service, the present study examines for the first time in young athletes the kinematic characteristics of the lower limbs. It is expected that by improving the movement of the legs, a better driving of the foot can be produced, which can enhance the rotation of the shoulder resulting in a better service, as concluded by Girard, Micallef \& Millet, (2005).

\section{METHODS}

Twelve (6 males, 6 females) right handed young tennis players, aged 12-16 participated in this study, that are playing in tournaments of the Hellenic Tennis Federation (age: $13,8 \pm 1,22$ years, height: $167,5 \pm 10,11 \mathrm{~cm}$, mass: $55,20 \pm 11,15$ $\mathrm{kg}$ ) and 12 professionals who participated in Roland Garros, 6 men and 6 women.

\section{Instrumentation}

The Optitrack kinematic optical analysis system (Natural point Systems Inc., USA) was used to conduct the research. The system uses 9 infrared cameras (Flex 3, Natural Point Systems, USA) with a sampling frequency of $100 \mathrm{~Hz}, 0.3$ Megapixel resolution ( $640 \times 480$ pixels). The system software Arena (V.1.15, Natural Point Inc., USA) was implemented for all measurements.

\section{Experimental set-up}

The subjects performed a standard warm-up, followed by a 10-minute working out of all three different serves. The athletes then performed the three different services, flat, slice and topspin with three attempts each, which were recorded. The best attempt that was considered representative to analyze was that in service, the ball had to pass over the line of a $0.914 \mathrm{~m}$-high tape. 
The three-dimensional space was first calibrated using a calibration wand. A total of 34 markers were placed on the head, the trunk, the shoulders, the elbow, the wrists, the pelvis, the hip, the knee, the shank and the feet. Based on the $3 \mathrm{D}$ coordinates of the reflective markers, the skeleton was represented in all frames of motion throughout the 3-D space. Skeleton motion was digitally stored in video format. Hence, video files were then used to calculate the time of each type of serve.

For professional athletes, video analysis was used and time was measured using the max TRAQ Lite.

\section{RESULTS WITH DISCUSION}

The present study aimed to focus on the lower limps and biomechanically analyze the time from the maximum knee flexion to the point of contact with the ball in the three different services, flat, slice and topspin, in young athletes aged 12-16 and high level professional athletes who participated in the main draw of Rolland Garros.

From the results in figure 1 , we conclude that the flat service took the shortest time $33.67 \mathrm{~ms}$ and this is attributed to the fact that it is used mainly as a first service, which means that it is performed with more power and speed. The slice service took $34.92 \mathrm{~ms}$ and the topspin $35.16 \mathrm{~ms}$ due to the higher knee flexion during the preparation phase of these services, which are usually performed as second.

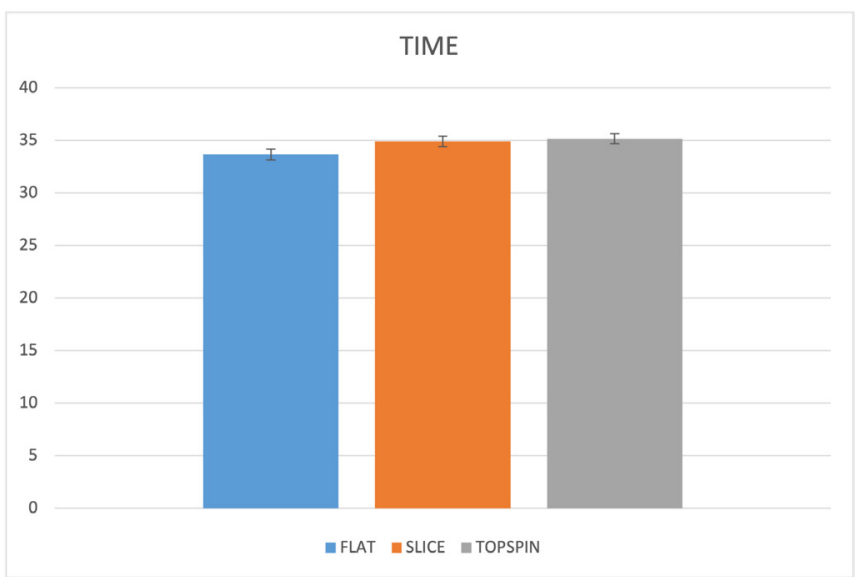

Figure 1. Time from the maximum bending of the knees to the point of contact with the ball, in young athletes $(n=12)$.

Knee extension, which is a sequence of their maximum flexion, is one of the most important movements in performing tennis service (Elliot et al., 1995). This can increase the speed of the leg extension through the use of stored energy and help move the lower limbs to lead the player towards the ball (Girard et al., 2005).

Comparing the time of young athletes with mean $34.56 \mathrm{~ms}$ with the time of high level athletes with mean $30.67 \mathrm{~ms}$, figure 2 , the results showed that the professionals performed the service with much faster and sharper knee extension than the young athletes having a significant difference.

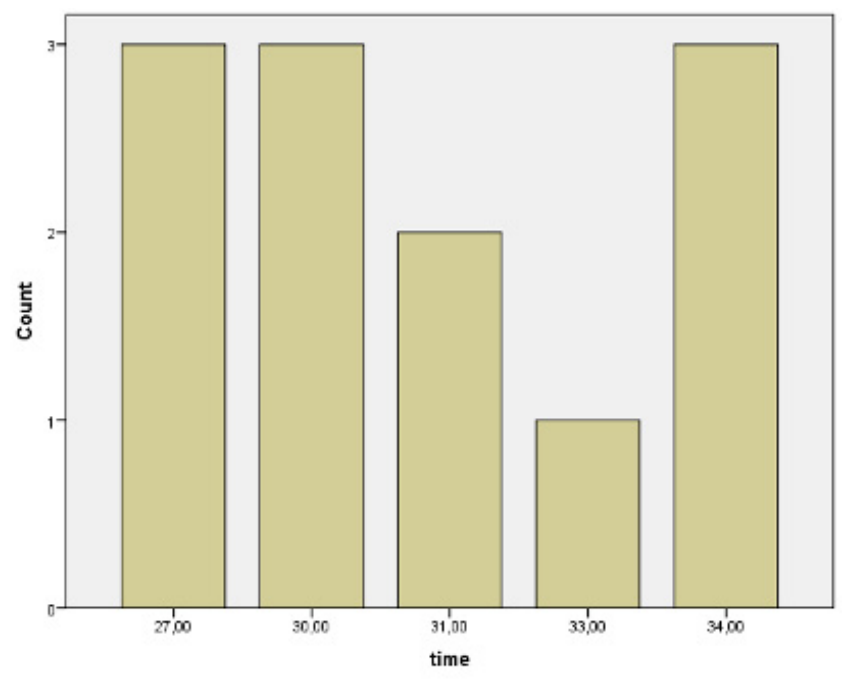

Figure 2. Time from maximum bending of the knees to the point of contact with the ball, in professional athletes $(n=12)$.

Due to the large degree of extension of the knees in a minimum of time, it is logical that high speeds of movement of the joints are created. Thus, the lack of strong knee extension after the phase of maximum knee flexion would reduce the speed of the racket and therefore the speed of the ball after contact (Reid et al., 2008). Therefore, the increase in knee extension speed seems to be very important in the early stages of development of tennis athletes, so that the pace of service movement is automated and with the development of young athletes more burdens and pressures are added with in order to increase the efficiency of the service, but also to facilitate the transfer of forces from the ground to the contact hand, thus increasing the speed of movement.

From a training point of view, a quick movement of the legs from an angle of inclination to the knees of $90-110^{\circ}$ and then with the maximum extent reaching the contact with the ball, is defined as a good practice according to the findings of (Elliot \& Reid, 2004). An increasingly intense movement of the legs causes the upper end of the racket to rotate faster, leading to a greater displacement towards the ground (Elliot et al., 1986; Reid et al., 2008). This in turn improves the possibility of higher impact velocities, as although the racket moves away from the ball, the increased storage of elastic energy in the internal turns of the shoulder allows for greater acceleration and leads to contact (Elliot et al., 1986, Roetert \& Groppel, 2001; Reid et al., 2008). Thus, the lack of strong knee extension after the counter-movement phase would reduce the speed of the racket and therefore the speed of the ball after its impact (Reid et al., 2008).

\section{PROPOSALS}

In the present study, differences were found in the three different types of service, which means that young athletes, in attempting to spin the ball and particular in slice and topspin serves used as second serves, they should have more knee flexion than flat service. 
So young athletes will have to constantly improve their coordination of movement until they reach the point of contact with the ball. This means that the time required to perform the phase from bending the knees to the point of contact will be reduced. So the faster the movement is performed after the knee flexion, the more efficient the service will be.

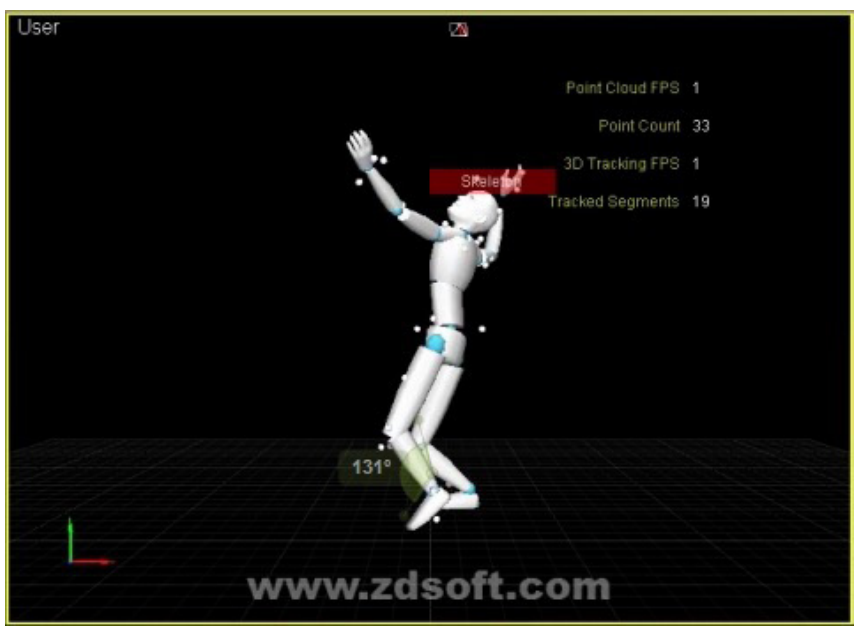

Figure 3. Digital representation of maximal knee flexion when performing flat service.

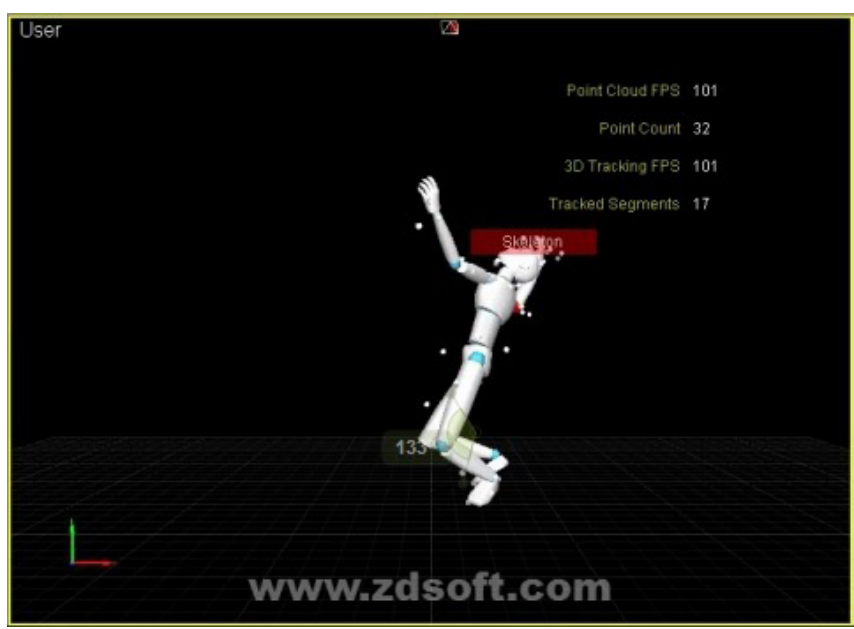

Figure 4. Digital representation of maximal knee flexion when performing topspin service.

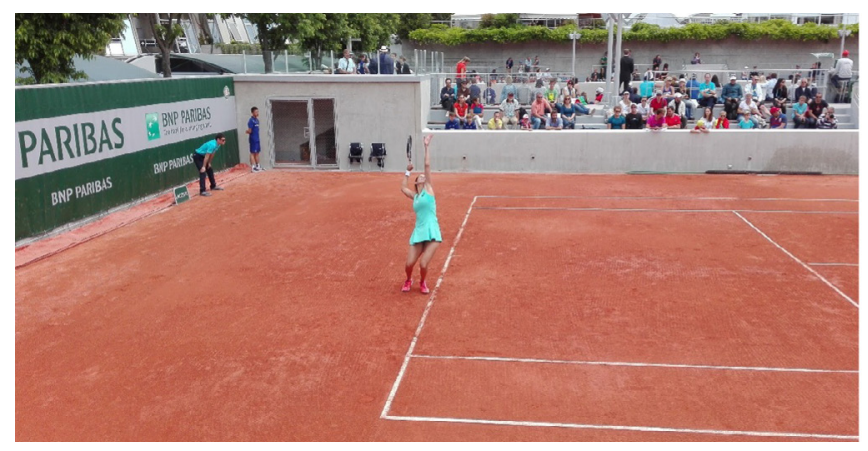

Figure 5. The maximum bending of the knees.

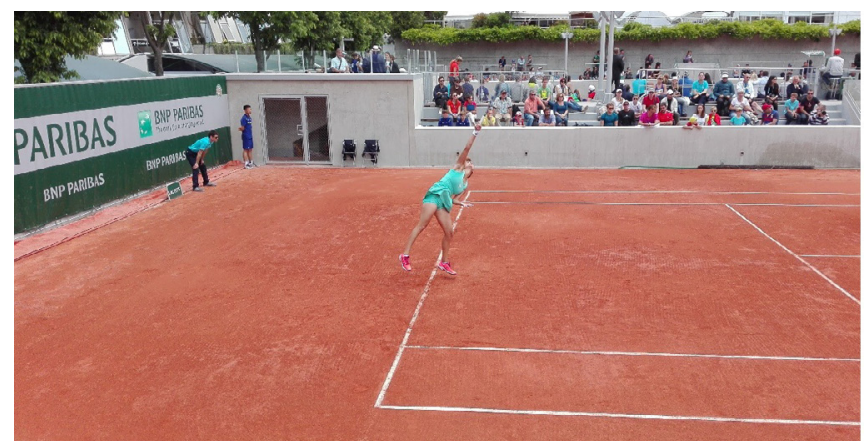

Figure 6. The point of contact with the ball.

\section{REFERENCES}

Abrams, G. D., Sheets, A. L., Andriacchi, T. P., \& Safran, M. R. (2011). Review of tennis serves motion analysis and the biomechanics of three serve types with. implications for injury. Sport Biomechanics, 10, 378-390. https://doi.org/10.1080/14763141.2011.629302

Cross, R., \& Lindsey, C. (2005). Technical tennis: Racquets, strings, balls, courts, spin, and bounce (pp. 119-152). Vista, CA: Racquet Tech Publishing.

Elliott, BC., Marhs, T., \& Blanks, B. (1986). A three-dimensionalcinematographical analysis of the tennis serve. Int J Sport Biomech. 2: 260-270. https://doi.org/10.1123/ijsb.2.4.260

Elliott, B.C., Marshall, R.N., \& Noffal, GJ. (1995). Contributions of upper limb segment rotations during the power serve in tennis. J Appl Biomech. 11: 433- 442. https://doi.org/10.1123/jab.11.4.433

Elliott, B., Fleisig, GS., Nicholls, R., \& Escamilla, R. (2003). Technique effects on upper limb loading in the tennis serve. J Sci Med Sport. 6 (1):76-87. https://doi.org/10.1016/S1440-2440(03)80011-7

Elliott, B., Reid, M., \& Crespo, M. (2009). Technique Development in Tennis Stroke Production London, UK: International Tennis Federation.

Girard, O., Micallef, J.P., \& Millet, G.P. (2005). Lower-limb activity during the power serve in tennis: effects of performance level. Med Sci Sports Exerc. 37 (6):1021- 1029.

Reid, M., Elliott, B., \& Alderson, J. (2008). Lower-limb coordination and shoulder joint mechanics in the tennis serve. Med Sci Sports Exerc. 40 (2):308-315. https://doi.org/10.1249/mss.0b013e31815c6d61

Roetert, E.P., \& Groppel, J.L. (2001). Mastering the kinetic chain. In: Roetert EP, Groppel JL, eds. World Class Tennis Technique. Champaign, IL: Human Kinetics; 99- 113.

Copyright (C) 2021 Christos Mourtzios, Ioannis Athanailidis, Eleftherios Kellis \& Vasileia Arvanitidou

\section{(c) (i)}

This text is under a Creative Commons BY 4.0 license

You are free to Share - copy and redistribute the material in any medium or format - and Adapt the content - remix, transform, and build upon the material for any purpose, even commercially under the following terms:

Attribution: You must give appropriate credit, provide a link to the license, and indicate if changes were made. You may do so in any reasonable manner, but not in any way that suggests the licensor endorses you or your use. 